Rhode Island College

Digital Commons @ RIC

\title{
Neuroscience Nurses' Perceptions of the Barriers to Identifying and Treating Pain in Acutely Brain-Injured Adult Patients
}

Kimberly A. lannotti

Rhode Island College

Follow this and additional works at: https://digitalcommons.ric.edu/etd

Part of the Other Nursing Commons

\section{Recommended Citation}

lannotti, Kimberly A., "Neuroscience Nurses' Perceptions of the Barriers to Identifying and Treating Pain in Acutely Brain-Injured Adult Patients" (2015). Master's Theses, Dissertations, Graduate Research and Major Papers Overview. 121.

https://digitalcommons.ric.edu/etd/121

This Major Paper is brought to you for free and open access by the Master's Theses, Dissertations, Graduate Research and Major Papers at Digital Commons @ RIC. It has been accepted for inclusion in Master's Theses, Dissertations, Graduate Research and Major Papers Overview by an authorized administrator of Digital Commons @ RIC. For more information, please contact digitalcommons@ric.edu. 


\section{NEUROSCIENCE NURSES' PERCEPTIONS OF THE BARRIERS TO IDENTIFYING AND TREATING PAIN IN ACUTELY BRAIN-INJURED ADULT PATIENTS}

by

Kimberly A. Iannotti

A Major Paper Submitted in Partial Fulfillment of the Requirements for the Degree of

Master of Science in Nursing

in

The School of Nursing

Rhode Island College

2015 


\begin{abstract}
Pain management for the critically ill adult can be daunting. Numerous factors contribute to this challenging process including altered level of consciousness (LOC), inability to speak, life support measures, family input, level of sedation, paralyzing agents, restraints, cognitive impairment, and numerous other factors. The current practice related to pain management in the neurologically critically ill adult patient population is limited by inadequate pain scales, altered neurological status, and atypical pain-associated behaviors. Additionally, nurses are challenged by unclear practice guidelines. The critical care nurse is required to assess and manage pain, as well as implement specific interventions based on the patient's exhibiting characteristics or behaviors. The purpose of this study was to explore the neuroscience nurses' perception of the barriers to identifying and treating pain in the acutely brain-injured adult patient. Participants were registered nurses working on a Neurocritical Care Unit. The methodology included two short answer questions and 15 Likert format questions rating the frequency of specific barriers. Nurses reported declining neurological status and subjective assessment tools as the most frequently seen barriers to pain assessment and management. Development of pain assessment measures in the brain-injured acutely ill adult patient continues to be important. The need for nurse-driven research to explore alternate measures to identify pain in the neurological patient is indicated. Implications for advanced practice are discussed.
\end{abstract}




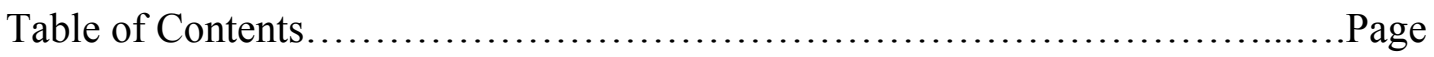

Background/Statement of the Problem...........................................

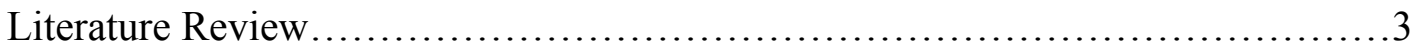

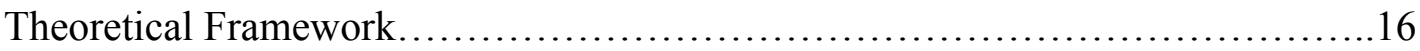

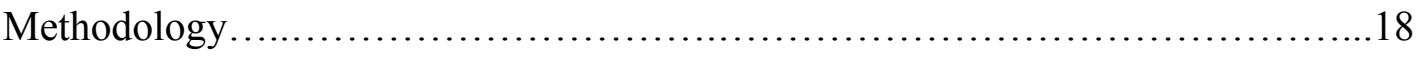

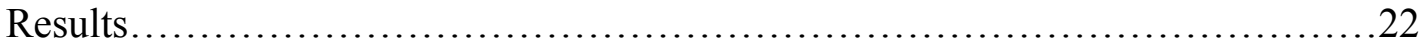

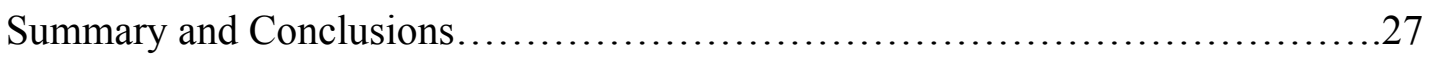

Recommendations and Implications for Advanced Practice Nursing................30

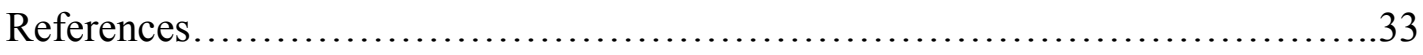

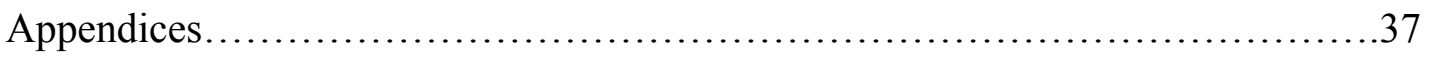


Neuroscience Nurses' Perceptions of the Barriers to Identifying and Treating Pain in Acutely Brain-Injured Adult Patients

\section{Background/Statement of the Problem}

Pain management for the critically ill adult can be a daunting process. Numerous factors contribute to this challenging process, including altered level of consciousness (LOC), inability to speak, life support measures, family input, level of sedation, paralyzing agents, restraints, cognitive impairment, and numerous other factors. The current practice related to pain management within the neurologically critically ill adult patient population is limited by inadequate pain scales, altered neurological status, and atypical pain-associated behaviors. Additionally, nurses are challenged by unclear practice guidelines and must be diligent that as needed (PRN) medications are administered in accordance with the standard of care. The critical care nurse is required to assess and manage pain, as well as implement specific interventions based on the patient's exhibiting characteristics or behaviors. This interaction must be synergistic.

Pain often occurs in critical care patients and is one of the most clinically challenging problems for critical care nurses (Helms \& Barone, 2008). Nurses have a moral obligation to assess patients' level of pain and comfort and provide the appropriate treatment as indicated. The ethical principles of beneficence and nonmaleficence obligate health care professionals to provide pain management and comfort to all patients (Herr, Coyne, McCaffrey, Manworren, \& Merkel, 2011). To provide the best possible care for patients experiencing pain, nurses must understand the physiology of pain, the diversity of patient responses, and the rationale for choices of pain control methods (Helms \& Barone, 2008). The Joint Commission lists pain management as one of its 
patient-specific standards. This standard requires that organizations recognize the rights of patients to appropriate assessment and management of pain. In critical care, this is an especially complex and challenging task as many of these patients are unable to selfreport their level of pain. In patients who cannot communicate verbally, it is strongly recommended that pain be assessed with validated tools based on behavioral and physiological indicators (Herr et al., 2011).

Pain is a major concern in the brain-injured, critically ill patient. Untreated pain has physiological consequences that may alter cerebral perfusion pressure and lead to permanent brain damage (Roulin \& Ramelet, 2012). In the past, it had been thought that pain from intracranial surgery was minimal, but more recent investigations have found such pain to be more intense, and the effect on the quality of recovery more profound, than previously thought (Gottschalk \& Yaster, 2009). Significant pain should be assumed to be present in neurocritically ill patients and assiduous assessment of pain using validated assessment tools is the first step toward appropriate pain management (Gelinas, Klein, Naidech, \& Skrobik, 2013).

Several important questions can be raised, including: What are the barriers that Intensive Care Unit (ICU) nurses perceive as impacting pain management in the ICU with the brain-injured adult patient population? The purpose of this study was to explore the neuroscience nurse's perception of the barriers to identifying and treating pain with the acutely brain-injured adult patient.

The review of the relevant literature will be presented next. 


\section{Literature Review}

The databases searched for this literature review included PubMed, CINAHL, OVID and the American Association of Critical Care Nurses website, from 2005 to 2014. Keywords used were brain-injured adult, pain pathophysiology, FLACC, pain assessment, neurocritical care, synergy model, critical care nursing, behavioral pain scale, and authors Puntillo and Gelinas.

\section{Understanding Pain}

"Pain is an unpleasant sensory and emotional experience associated with actual or potential tissue damage or described in terms of such damage" (American Pain Society, n.d., p. 4). This definition illustrates that pain is a subjective experience and emphasizes that the individual's pain experience is complex and includes multi dimensions (American Pain Society). The perception of pain is called nociception. Nociceptors, also called pain or sensory receptors, are free nerve endings that respond to painful stimuli by sending an impulse through the spinal cord to the brain (American Pain Society). The brain perceives this transmission of signals as pain. These impulses may arise from skin, muscle, joints, arteries, or the viscera. The nociceptors respond to stimuli that may originate from chemical, mechanical and thermal trauma (McCance, Huether, Brashers, $\&$ Rote, 2010). Pain may also occur from an aberrant signal process along the tract of the nervous system. This type of pain is referred to as neuropathic pain or non-nociceptive pain (American Pain Society, n.d.). The brain's perception of pain is that of an uncomfortable awareness of some part of the body that is characterized as an unpleasant sensation (American Pain Society). Tolerance to pain varies by the individual and may 
be influenced by the person's cultural perceptions, expectations, role behaviors, and physical and mental health (McCance et al., 2010).

The duration of pain may be acute or chronic. Acute pain is typically nociceptive. An example is a cut on the finger where the cause results from tissue injury. Acute pain is a protective mechanism that alerts the individual that injury has occurred; the onset is sudden and dissipates once the stimulus is removed and the tissue has healed (McCance et al., 2010). Chronic pain also can be nociceptive but it is further defined as prolonged, usually lasting at least three months (McCance et al.). Chronic pain is recognized as pain that extends beyond the period of healing with levels of pathology that are insufficient to explain the presence or extent of pain (American Pain Society, n.d.). Chronic pain may also be neuropathic, caused from malignancy, or arising from a variety of non-lifethreatening conditions. In some instances, chronic pain exists with no apparent cause (American Pain Society). Clinically, pain is classified by mechanism as nociceptive or non-nociceptive and by duration as either acute or chronic (McCance et al., 2010).

Pain is the most common complaint reported by patients and is a sensual and perceptual phenomenon that causes suffering and emotional risk (Swieboda, Filip, Prystupa, \& Drozd, 2013). To the patient, pain means disease and suffering and it can alter a person's life, reduce the quality of life, and also have an impact on the entire family (Swieboda et al.). The experience of pain is very individual and varies under different circumstances. Pain intensity also varies by the individual and is difficult to measure because an individual's perception of pain depends on the emotional state and the circumstances under which the pain arose. Factors that influence the individual perception of pain are arousal, attention, distraction and expectation (Swieboda et al.). 
When assessing pain from a clinical perspective, it is useful to describe the pain in terms of its location, intensity, duration and quality. These clinical descriptors are important to aid in identifying the possible cause of pain. Location may not always correspond to the site of injury. Pain intensity is evaluated with a scale and divides pain into ranges from strong to moderate, weak and no pain. Duration of pain is measurable and allows differentiation between acute and chronic pain (Swieboda et al., 2013). Examples of quality descriptors are sharp, dull, or burning. "Pain is more than a physical phenomenon, the psychological, social and spiritual aspects of pain should also be considered" (Swieboda et al., p. 5). Thus, the approach to understanding pain should be multi-dimensional. The assessment of pain needs to be comprehensive and include its physical effects, functional effects, psychosocial factors and spiritual aspects (Swieboda et al.).

Helms and Barone (2008) discussed the physiology and treatment of pain. Pain theories are presented, pathways of pain are shown, and a discussion of acute versus chronic pain is examined. Acute pain serves a biologic purpose by providing a warning that illness or injury has occurred. The pain is usually confined to the affected area and is limited over time (Helms \& Barone). Physical signs manifest acute pain and include increased heart rate, increased respiratory rate, sweating, dilated pupils, restlessness and apprehension. Chronic pain is prolonged beyond the expected healing time. It may be continuous like with arthritis or intermittent as with migraine headaches. Untreated or poorly treated pain may lead to harmful physiological effects such as inadequate sleep, anxiety, increased myocardial oxygen demand and immunosuppression. Pain is unique 
for each person and encompasses a person's physical, psychological, cognitive, and emotional network (Helms \& Barone).

\section{Pain and Pain Assessment in the Critically III}

"Pain often occurs in critical care patients and is one of the most clinically challenging problems for critical care nurses" (Helms \& Barone, p. 38). It is estimated that of the five million patients admitted to the ICU each year, $71 \%$ remember experiencing pain during their stay (Stites, 2013). Appropriate treatment of pain leads to decreased ventilator days, decreased rates of nosocomial infections and increased patient satisfaction (Stites, 2013).

The American College of Critical Care Medicine recently published guidelines for the management of pain, agitation, and delirium (Riker \& Fraser, 2013).

Recommendation number one reads that pain should be routinely monitored in all ICU patients. Assessing and documenting the presence or absence of pain is associated with improved outcomes (Riker \& Fraser) and the standard for pain assessment is self-report using a numeric scale. For patients unable to self-report using a numeric scale, The Behavioral Pain Scale (BPS) and the Critical Care Pain Observation Tool (CPOT) are found to be reliable in this patient population (Stites). It is suggested in the guidelines that vital signs not be used for pain assessment but may be used as a cue to further assess pain. Vital signs do not correlate with either patient self-report or behavioral scales, but may identify the need to further evaluate the presence of pain (Riker \& Fraser).

The American Association for Critical-Care Nurses (AACN) issued a practice alert in February 2014 concerning pain assessment in the critically ill (AACN Practice Alert, 2014). This nursing assessment is an expected practice and nursing actions fall 
into several categories: eliciting self-report, utilizing a behavioral pain scale, and using a proxy (AACN Practice Alert). Self-reporting pain has long been considered the gold standard for assessment but many adult patients in the ICU cannot self-report pain and rely on their caregivers to assess and treat the assumed pain. The frequent inability to self-report makes assessing pain in critically ill patients a challenge. The AACN expectation assumes that the critical care nurse has been educated on the use of a validated pain assessment tool and that a pain management protocol is in place that includes pharmacologic and nonpharmacologic strategies.

Puntillo, Smith, Arai, and Stotts (2008) studied nurses' perspectives of patient symptoms in intensive care units. The study included 22 ICU nurses who worked in two ICUs at a tertiary medical center in the western United States: a 24-bed medical-surgical ICU and a 16-bed cardiac ICU. This prospective, descriptive study explored how nurses assessed and treated distressing symptoms in the critically ill population. Taped interviews captured the nurses' description of their patients' signs and symptoms and how they managed these characteristics. Themes were identified and it was concluded that critically ill patients experienced a broad range of symptoms. The authors noted that continued attempts to validate nonverbal measures are warranted because lack of measures may adversely affect symptom treatment. Further heightened awareness and increased nursing education is indicated.

Puntillo et al. (2009) reviewed the various ways to evaluate the pain experienced by ICU patients. Again, self-report was identified as the most reliable method of evaluating pain. In the case of the patient unable to self-report, other objective validated assessment measures of pain are indicated such as valid and structured tools. The authors discussed 
the importance of evaluation tools being made available to the nurse caring for the patient. Validated behavioral assessment tools include the PAIN algorithm (pain, assessment, intervention and notation), the Behavioral Pain Scale (BPS), and the CriticalCare Pain Observation Tool (CPOT). Both the BPS and CPOT have been tested and validated for use with ICU patients who are unable to communicate (Stites, 2013).

\section{Pain Assessment in Patients Unable to Self-Report}

Herr et al. (2011) developed a position statement that includes clinical practice guidelines for patients unable to self-report. The authors discussed the ethical tenets involved in the patient's right to pain treatment and stated that nurses are integral to ensuring assessment and treatment of these vulnerable populations. General recommendations were offered as a hierarchy of techniques that nurses should follow. The hierarchy starts with the self-report and then recommends that patient behaviors be observed in the absence of the self-report. When the self-report is limited or absent, further investigation is recommended. Next in the hierarchy is to search for potential causes of pain. Many pathologic conditions are known to cause pain, as are common procedures such as surgery, trauma, wound care and positioning/turning. The third step in the hierarchy is to observe patient behaviors and includes the use of behavioral pain scale tools. Behaviors vary between various subpopulations. Proxy reporting by family members or professional caregivers is also considered to be credible information that may help identify the presence of pain in a patient unable to self-report. Parents, caregivers, and family members may know an individual's typical behavioral response to pain and therefore play an essential role in recognizing pain in the patient unable to self-report (Herr et al.). 
Stites (2013) conducted a comprehensive search on the reliability and validity of observational pain scales used in critically ill adult patients. A search of the literature between 2000 and 2010 produced 1120 articles, with 17 meeting the inclusion criteria. The author focused on adult patients in the ICU and excluded those that dealt with chronic pain. The literature review focused on the pain assessment tools that have been tested on patients in the ICU. Two of the instruments found and highlighted in the study included the Behavioral Pain Scale (BPS) and the Critical-Care Pain Observation Tool (CPOT).

The BPS is based on the unique behaviors present in the critically ill adult patient undergoing noxious stimulus. The BPS is composed of three behavioral domains: facial expression; movements of upper limbs; and compliance with mechanical ventilation. Four behavioral characteristics are assessed from each of the three domains with scores from one to four, with the higher number indicating higher levels of discomfort. Total scores range from a low of three (no pain) to a high of 12 (maximum pain). The author presented five studies that validated the BPS's effectiveness in the ICU patient. The CPOT is a pain assessment tool designed for use in both intubated and non-intubated critical care patients. The CPOT measure, which will be described in depth in an upcoming section, was determined to be superior when compared with other behavioral pain assessment tools available.

Voepel-Lewis, Zanotti, Dammeyer, \& Merkel (2010) studied the reliability and validity of the Face, Legs, Activity, Cry, Consolability (FLACC) Behavioral Scale for use with critically ill patients. The authors devised a prospective, observational study to evaluate the reliability and validity of the FLACC scale in critical ill adults and children. 
The FLACC scale is widely recognized and uses behavioral characteristics that are reliably associated with pain in children (Voepel-Lewis et al.). The study included a total of 73 observations obtained on 29 critically ill adults and eight children. The observers were three intensive care nurses who simultaneously and independently observed and scored pain behaviors during painful procedures and before administration of analgesics. Two of the nurses used FLACC and one used other behavioral pain assessment tools. The nurses had no knowledge of the scores of their fellow nurses. The authors found that the FLACC scores correlated significantly with the other behavioral tools and that FLACC scores decreased significantly after administration of an analgesic. The study also found that agreement was excellent between observers for each category of the FLACC supporting the reliability of the tool.

\section{Pain Management in the Neurocritically Ill}

Gelinas et al. (2013) defined the neurocritically ill patient as one with a central neurological injury such as traumatic brain injury (TBI), stroke, intracranial hemorrhage, or one with a primary neurological illness with predominantly peripheral manifestations such as Guillain Barré or myasthenia gravis. Outcome studies are lacking and further research efforts are urgently needed to develop and validate more appropriate assessment tools for this highly vulnerable patient population (Gelinas et al.). Neurocritically ill patients represent a special population that is likely to be unable to self-report pain. Pain behaviors like muscle rigidity and grimacing may be absent in the critically ill patient with a brain injury due to an altered level of consciousness, endotracheal intubation, or the administration of paralytics or sedatives (Lee, Oh, Suh, \& Seo, 2013). 
Roulin and Ramelet (2012) conducted an integrative review of pain indicators that are specific to the brain-injured adult. Seven articles met the inclusion criteria and were critically appraised for quality. Six pain indicators were identified from the seven studies, including facial expression, a motor response to noxious stimulation, rigidity and startled movements, asynchrony with ventilation, whimpering or moaning. Also identified were non-specific indicators such as difficulty to console and non-cooperative behavior. The authors also derived descriptors of pain for each of the six indicators. They concluded that the relevance of physiological indicators remains controversial with this patient population and requires further investigation in order to be confirmed by empirical data. There was also a lack of consensus related to the descriptors for each indicator.

Dr. Celine Gelinas from McGill University Montreal, Quebec Canada developed the Critical-Care Observation Tool or CPOT. The CPOT was developed for the detection of pain in non-communicative critically ill adults, mechanically ventilated or not (Gelinas, Fillion, Puntillo, Viens \& Fortier, 2006). Four behavioral domains are assessed with the CPOT tool: facial expression movements; muscle tension; and vocal sound or ventilator compliance. Each domain includes three evidence-based behavioral descriptors that are scored from zero (relaxed) to two (very tense). Scores with CPOT range from zero (no pain) to eight (indicates the most pain). Stites (2013) reviewed the literature for pain assessment measures and found that seven studies had tested the reliability and validity of the CPOT. This tool was determined to be superior when compared with other behavioral pain assessment tools available. Stites concluded that although the CPOT has been deemed superior, the best tool has yet to be identified. 
Echegaray-Benites, Kapoustina, and Gelinas (2014) reported on the validation of the CPOT with brain surgery patients in a neurological intensive care unit. Although the CPOT demonstrated reliability and validity with elective brain surgery patients, this patient population is not representative of other brain-injured adults with altered level of consciousness. The authors concluded that further research is still needed in this later vulnerable group (Echegaray-Benites et al., 2014).

Arbour, Choiniere, Topolovec-Vranic, Loiselle, and Gelinas (2014) aimed to validate the use of vital signs for pain detection in critically ill Traumatic Brain Injured (TBI) patients. A repeated measure within subjects design was used. The sample size was 45 adult patients recently admitted to the ICU of a Level 1 trauma center with a TBI unit. Subjects were excluded if they had any type of motor paralysis or received a neuroblocking agent, a documented history of chronic substance abuse, a prior TBI or suspected brain death. The TBI participants were observed during two procedures routinely performed in the ICU: noninvasive blood pressure with cuff inflation (nonnociceptive) and turning/repositioning (nociceptive). For each procedure, participants were observed at three intervals: one minute before (baseline), during, and 15 minutes post procedure for a total of six assessments. Vital signs were recorded at each interval. The vital signs used for the study were: systolic and diastolic blood pressure, heart rate, respiratory rate, capillary saturation, end-tidal $\mathrm{CO} 2$ and intracranial pressure (ICP). The results indicated that significant fluctuations $(\mathrm{p}<0.05)$ in vital signs (diastolic BP, HR, and ICP) occurred across assessments, but they were similar during both procedures and the fluctuations occurred across assessments. The authors concluded that vital signs are not specific for pain detection. 


\section{Barriers to Nursing Assessment and Management of Pain}

Rejeh, Ahmadi, Mohammadi, Anoosheh, and Kazemnejad (2008) conducted a qualitative study that examined nurses' perceptions of the barriers and facilitators influencing the management of post-operative pain. The participants were Iranian nurses working in general surgery wards in three educational hospitals in Tehran City. Sample size was 26 nurses with five plus years of experience. Individual semi-structured interviews were conducted and the interviews were tape-recorded. Open-ended questions were used to allow the respondents to explain their own viewpoints and experiences. The opening question was "Please share with me how you care for your patient in pain." The investigators identified several themes that hindered post-operative pain management. Powerlessness, policies and rules of organization, physicians leading practice, times constraints, and limited communication were documented as the common themes shared by the participants. This study was limited to the viewpoint of the participants and generalization across a larger population of nurses within diverse settings is needed.

A qualitative study of the challenges faced by nurses in managing pain among ill patients in critical care was conducted by Subramanian, Allock, James, and Lathlean (2011). The study was based at a large acute teaching health care trust in the United Kingdom. Twenty-one nurses were selected from critical care settings and semi structured interviews were conducted. Study participants were selected using a purposive sampling method. The researchers sought nurses with diverse backgrounds and a wide range of work experience. One-to-one, tape-recorded, in-depth interviews using critical incident technique were conducted. Four main themes were identified, including lack of clinical guidelines, lack of structured pain assessment tool, limited autonomy in decision- 
making and the patient's condition itself. The study concluded that there is a need for nursing education on pain management.

As noted in the previous studies, nurses' knowledge of pain assessment appears to be lacking. Rose et al. (2012) aimed to document nurses' pain assessment and management practices. The objective of the study was to document the knowledge and perceptions of pain assessment and management practices of ICU nurses. A secondary objective was to determine factors associated with the use of behavior tools, nurses' knowledge of pain indicators, and nurses' awareness of pain management guidelines. A survey was administered that asked intensive care nurses to respond to a selfadministered questionnaire that addressed their perceived assessment skills and pain management practices. Specifically, the study participants where queried about their individual practices related to the use of behavioral scales and patient self-report tools as well as the factors associated with use of behavioral tools and the indictors of pain. The questionnaire also assessed the nurses' knowledge of local and international guidelines for pain assessment and management. The survey was sent to 3,753 ICU nurses and a total of $842(24 \%)$ responded. Study findings showed that nurses were significantly less likely $(\mathrm{n}=267 ; 33 \%)$ to use a pain assessment tool for patients unable to communicate than for patients able to self-report (33\% vs. 89\%). Significantly fewer participants ( $\mathrm{n}=$ $595 ; 74 \%$ ) rated behavioral pain assessment tools as moderately to extremely important compared with self-report tools $(\mathrm{n}=703 ; 88 \%)$. Few nurses $(\mathrm{n}=235 ; 29 \%)$ reported having knowledge of professional guidelines for pain assessment and management. The authors concluded that a substantial proportion of ICU nurses did not use pain assessment tools and were unaware of pain management practices. 
In summary, the incidence of pain in the critically ill adult is highly prevalent. Further complicating this issue is the population of patients who are unable to communicate their pain and discomfort and therefore pain may be poorly treated. Critical care nurses are challenged with assessing and managing pain within this vulnerable group of patients. When patients are unable to self-report, the staff nurse must utilize validated behavioral assessment tools. The literature revealed that nurses have identified multiple barriers to effective management of pain. Examples include lack of clinical guidelines, subjective pain assessment tools, insufficient knowledge and poor communication between physicians, nurses and patients. Effective education is needed to empower nurses and enhance their ability to treat pain in the critically injured adult patient. Barriers related to management of pain with the neurocritically ill patient are not well published and further examination is needed.

Next, the theoretical framework used to guide this study will be presented. 


\section{Theoretical Framework}

Synergy is an evolving phenomenon that occurs when individuals work together in mutually enhancing ways toward a common goal (Curley, 1998). The Synergy Model describes a framework for nursing practice where patient characteristics are linked to nurse competencies to achieve optimal patient outcomes. The purpose of the Synergy Model is to articulate nurses' contributions, activities, and outcomes with regard to caring for critically ill patients (McEwen \& Wills, 2011). According to the model, each person brings a unique cluster of personal characteristics to a healthcare situation. These characteristics, which include resiliency, vulnerability, stability, complexity, participation, and predictability, span the continuum of health and illness (Curley). Nursing competencies, derived from the needs of patients, can also be described in terms of essential continuums and include clinical judgment, advocacy, and moral agency, caring practices, facilitation of learning, collaboration, systems thinking, diversity of responsiveness, and clinical inquiry (Curley).

The outcomes are described on three levels: those relating to the patient, the nurse, and the system (McEwen \& Wills, 2011). Patient outcomes are related to function and include satisfaction and comfort. The nurse outcomes include presence or absence of complications, the extent to which care or treatment objectives were attained and physiological changes. The third outcome related to the system describes results in terms of recidivism and cost/resource utilization. According to the Synergy Model, when these patient characteristics match with the nurses' competencies, optimal patient outcomes are achieved (Curley, 1998). The Synergy Model was chosen as the theoretical framework for this project because of this key assumption. Critically ill neurologic patients display 
vulnerability and complexity. The nurse must possess clinical judgment, caring practices, systems thinking and collaboration. When these characteristics combine and "synergize", patient outcomes are maximized.

Next, the study methodology will be presented. 


\section{Methodology}

\section{Purpose}

The purpose of this study was to explore neuroscience nurses' perception of the barriers to identifying and treating pain with the acutely brain-injured adult patient.

\section{Design}

A mixed methods design was employed.

\section{Sample}

The study participants were critical care registered nurses working at the bedside in a 12-bed Neurocritical Care Unit. No exclusion criteria were identified.

\section{Site}

The study was conducted in a 700+ bed teaching not-for-profit hospital with a Level-1 trauma center located in the Northeastern United States. The neuro-critical care intensive care unit is a 12-bed unit that employs $35 \mathrm{RNs}$, two clinical managers and one assistant clinical manager. The unit is staffed with a one $\mathrm{RN}$ to two patient ratios throughout a 24-hour day with the ability to staff up based on patient acuity.

\section{Procedures}

Permission to conduct the study was granted by the Rhode Island Hospital Chief of Nursing, the Clinical Manager of the Neurocritical Care Unit, the Lifespan Institutional Review Board (IRB) and the Rhode Island College IRB. An IRB approved informational letter (Appendix A) describing the research project and purpose of the study was distributed along with a survey (Appendix B) to interested participants in the staff break room. After a brief introduction, the surveys, with the informational letter attached to each, were left in an envelope on the break room table. The surveys remained 
on the Neurocritical Care Unit for a one-week study period as communicated during the introduction. The letter explained that participation was voluntary and anonymous and included contact names and email addresses of the primary investigator and student researcher. The participants were given an opportunity to ask questions when the survey was initially introduced and contact names and numbers were made available for participants who had additional questions or who were not available on that day. Next, participants were instructed to complete the attached survey if they wished, and to deposit the completed survey in the provided sealed drop box. The completed surveys were collected by the nurse investigator and kept for data analysis for a 1 month period and will be stored at the RIC College of Nursing for three years. The blank surveys remained in the staff break room for a 1 week period and were then collected along with the completed surveys at the end of the study period. No incentive was offered for participation.

\section{Measurement}

Demographic questions included years of nursing experience, years of critical care experience and level of education (Appendix B).

Two open ended questions were used to explore what nurses identified as the most significant barriers to assessing and effectively managing pain in the neurocritically ill patient: "Can you describe how you typically assess pain in neurocritically ill patients who are unable to communicate?"; "What do you think are some of the barriers that you face as a nurse to effectively assessing and managing pain in neurocritically ill patients who are unable to communicate?". The work of Rejeh et al. (2008) helped guide the development of these two questions. 
Quantitative questions were constructed by the student investigator based on the literature review and particularly the work of Jho et al. (2014). The original measure developed by Jho et al. had been pilot tested and validated with a sample of nurses and physicians with expertise in cancer pain management. According to Jho et al. (2014), three major categories summarized the types of barriers experienced: patient; medical staff; and health care system. The specific behaviors within each of these three categories were identified by Jho et al. (2013) and modified by this author to represent the potential barriers of the study population. Further, Subramanian et al. (2011) described several categories of challenges faced by nurses when managing pain with the critically ill patient. These categories included lack of clinical guidelines, lack of structured pain assessment tools, and limited autonomy in decision making. This work by Subramanian et al. (2011) helped guide the refinement of the barriers originally identified by Jho et al., (2013) to reflect the critically ill patient.

As originally designed by Jho et al. (2013), questionnaire responses were organized on a 4-point scale, where 1 indicated never, $2=$ sometimes, $3=$ often, and $4=$ always. Participants were asked to rate each specific barrier using this scale to guide their responses.

\section{Data Analysis}

The data gathered from the survey was entered into a Microsoft Excel spreadsheet for the purpose of organization of the Likert scale questions. Basic descriptive statistics were used to examine the study variables. The open-ended questions were analyzed by identifying any common themes. The synergy model helped to organize these common themes by looking for the patient/nurse/organizational characteristics that the framework 
identifies. Themes provide a way of conveying what has been learned from the participant responses and capture an idea or concept (Bonnel \& Smith, 2014). Key points and direct quotes were included in the data analysis as direct quotes help to enrich the findings by enlightening the common themes.

Next, results will be presented. 


\section{Results}

Of the 35 possible neuro critical care nurses, 11 completed the survey $(31.3 \%)$.

The demographic characteristics of the participants are illustrated in Table 1.

Table 1

Demographic Characteristics of Participants $(N=11)$

\begin{tabular}{|l|l|c|}
\hline Demographic Variable & Category and Response & Percentage \\
\hline Age & $22-33: 6$ & $54.54 \%$ \\
$34-44: 4$ & $36.36 \%$ \\
& $45-55: 0$ & $0 \%$ \\
\hline Years as an RN & 56 or older: 1 & $9.09 \%$ \\
& $0-10: 10$ & $90.91 \%$ \\
& $11-20: 1$ & $9.09 \%$ \\
& 21 or more: 0 & $0 \%$ \\
& Diploma: 2 & $18.18 \%$ \\
& Associates: 1 & $9.09 \%$ \\
& Bachelors: 8 & $72.73 \%$ \\
& Masters: 0 & $0 \%$ \\
\hline
\end{tabular}

Over half of the respondents (55\%) were between the ages of $22-33$ years, $91 \%$ reported 0-10 years of nursing experience and 73\% held a bachelor's degree.

Next, the participants were asked to describe their nursing practice as it related to pain assessment and to share any barriers they face when assessing and managing pain with the neurocritically ill patient. The investigator designed the survey with the open- 
ended questions at the beginning to avoid the participants from having the identified barriers influence their short answer responses. A total of eight participants completed the short answer questions and three left this section blank. Five of the eight nurses answered that they used the CPOT or FLACC behavioral assessment tool as part of their practice. Other responses included: "facial grimacing and vital signs", "consider blood pressure, heart rate, respiratory rate, and factor in patients physical movement", "body actions and vital signs". Vital signs specifically were listed by three nurses as something they considered as part of their practice when assessing for pain. An example of two additional responses follows: "I find the CPOT assessment tool to be more helpful than FLACC. I also find the sedation/analgesia protocol helpful with effective pain management"; "When family is present I have utilized their knowledge of the patient to find more about pain habits". 
Table 2 illustrates the responses from participants to the second question asking them to share any barriers faced when assessing and managing pain with the neurocritically ill patient.

Table 2

Survey Responses: Nurse Identified Barriers $(n=8)$

\begin{tabular}{|l|l|}
\hline 1. & Blood pressure not considered pain indicator. \\
\hline 2. & Not enough support from licensed practitioners. \\
\hline 3. & Over sedation and minimal sedation tools \\
\hline 4. & The quick decline in neurological patients \\
\hline 5. & Pharmacy policy not allowing RNs to use their own assessment skills/critical care \\
\hline 6. & thinking \\
\hline 7. & Lecreased level of consciousness leads to a CT scan. \\
\hline 8. & Not wanting to bother anyone; limited knowledge about medicine. \\
\hline
\end{tabular}

Nurse responses were mixed and ranged from policy issues like pain protocols to patient related issues like level of consciousness and to system issues like pharmacy verification timeframes. Although the responses varied, a common theme emerged when looking at the short answer questions combined. Multiple nurses responded that vital signs are used as an indicator of pain.

Next, respondents were asked to respond to a series of questions related to how frequently they encountered specific barriers to pain assessment. The specific barriers were grouped into 3 categories: patient, medical staff and health care system barriers. 
Table 3 illustrates the participants' responses to each of the 15 potential barriers to pain assessment and the mean score for each.

Table 3

Frequencies and Mean Scores $(N=11)$

\begin{tabular}{|c|c|c|c|c|c|}
\hline & $\begin{array}{c}\text { Never } \\
1\end{array}$ & $\begin{array}{c}\text { Sometimes } \\
2 \\
\end{array}$ & $\begin{array}{c}\text { Often } \\
3 \\
\end{array}$ & $\begin{array}{c}\text { Always } \\
4 \\
\end{array}$ & $\begin{array}{l}\text { Mean } \\
\text { Scores } \\
\end{array}$ \\
\hline \multicolumn{6}{|l|}{ Patient Related Barriers } \\
\hline $\begin{array}{l}\text { 1. Declining neurological } \\
\text { status of patient }\end{array}$ & 0 & 1 & 6 & 4 & 3.27 \\
\hline $\begin{array}{l}\text { 2. Family members at the } \\
\text { bedside }\end{array}$ & 1 & 7 & 2 & 1 & 2.27 \\
\hline $\begin{array}{l}\text { 3. Effect of patient sedation } \\
\text { level }\end{array}$ & 0 & 3 & 7 & 1 & 2.82 \\
\hline $\begin{array}{l}\text { 4. Patient has medication } \\
\text { tolerance }\end{array}$ & 0 & 9 & 2 & 0 & 2.18 \\
\hline \multicolumn{6}{|l|}{$\begin{array}{l}\text { Medical Staff Related } \\
\text { Barriers }\end{array}$} \\
\hline 5. Subjective assessment tools & 0 & 1 & 7 & 3 & 3.18 \\
\hline 6. Insufficient RN knowledge & 0 & 10 & 0 & 1 & 2.18 \\
\hline 7. Inadequate $\mathrm{RN}$ experience & 2 & 5 & 3 & 1 & 2.27 \\
\hline 8. RN time constraints & 1 & 7 & 3 & 0 & 2.18 \\
\hline $\begin{array}{l}\text { 9. } \mathrm{RN} \text { reluctance to use } \\
\text { opioids }\end{array}$ & 3 & 5 & 2 & 1 & 2.09 \\
\hline $\begin{array}{l}\text { 10. MD reluctance to prescribe } \\
\text { opioids }\end{array}$ & 1 & 6 & 2 & 2 & 2.45 \\
\hline \multicolumn{6}{|l|}{$\begin{array}{l}\text { Health Care System Related } \\
\text { Barriers }\end{array}$} \\
\hline $\begin{array}{l}\text { 11. Stock issues with } \\
\text { medication in Omnicell }\end{array}$ & 0 & 8 & 2 & 1 & 2.36 \\
\hline 12. Inadequate staffing & 1 & 8 & 2 & 0 & 2.09 \\
\hline $\begin{array}{l}\text { 13. Inadequate pain } \\
\text { assessment tools }\end{array}$ & 0 & 6 & 4 & 1 & 2.55 \\
\hline $\begin{array}{l}\text { 14. Incorrect medication } \\
\text { indication listed on order }\end{array}$ & 2 & 6 & 3 & 0 & 2.09 \\
\hline $\begin{array}{l}\text { 15. Pharmacy verification time } \\
\text { frame for new med order }\end{array}$ & 0 & 2 & 8 & 1 & 2.91 \\
\hline
\end{tabular}

The highest mean score of 3.27 or greatest frequency was given to the patient related barrier of declining neurological status (question 1) under patient related barriers. 
A total of 6 nurses, or $55 \%$ of the total participants, reported that they often find and 4 nurses, or 36\%, that they always find a patient's neurological status as a barrier to pain assessment and management. Question 5 had a mean score of 3.18 and shows that 10 nurses $(91 \%)$ find that they often $(n=7 ; 64 \%)$ or always $(n=3 ; 27 \%)$ find subjective assessment tools as a barrier to pain management. Of interest, question 15 that refers to a system process that requires pharmacy to verify new orders in a timely manner was identified by nine nurses as a barrier often $(n=8)$ or always $(n=1)$. The lowest mean scores or less frequent barriers were seen first with question 9 under medical staff related barriers. A mean score of 2.09 related to RN reluctance to use opioids. Questions 12 and 14 under health care system related barriers also had a mean score of 2.09. Inadequate staffing and incorrect medication indication listed on order were reported as being a barrier only sometimes.

Next, summary and conclusions will be presented. 


\section{Summary and Conclusions}

The incidence of pain in the critically ill adult is highly prevalent. Further complicating this issue is the population of patients who are unable to communicate their pain and discomfort and therefore may be poorly treated for pain. Critical care nurses are challenged with assessing and managing pain within this vulnerable group of patients. When patients are unable to self-report, the staff nurse must utilize validated behavioral assessment tools. The purpose of this research study was to explore neuroscience nurses' perception of the barriers to identifying and treating pain with the acutely brain-injured adult patient.

The study participants were neurocritical care registered nurses employed in the Neurocritical Care Unit at Rhode Island Hospital. Of the 35 potential participants, 11 registered nurses completed the survey (31\%). The majority of respondents were between the ages 22-33 years old, held a bachelor's degree and had less that 10 years nursing experience. The respondents completed a survey that asked them to briefly describe how they assess pain, to identify some of the barriers faced when assessing pain in the neurological patient, and to rate on a Likert scale how frequently they encountered specific barriers. The study participants identified a patient's declining neurological status as the barrier to pain assessment and management most often seen (mean $=3.27$ out of four). Participants also identified subjective assessment tools as a barrier that is often experienced (mean score 3.18 out of four). Pharmacy verification time frame for new medication order also ranked high with a mean score of 2.91. Less frequently seen barriers included RN reluctance to use opioids, inadequate staffing, and incorrect medication indication listed on order (mean scores 2.09). 
The brief open-ended questions were completed by 8 of the 11 study participants (73\%). The short answer questions revealed that most of the nurses who participated reported that they used a behavioral pain assessment tool in their practice of pain assessment $(\mathrm{n}=5 ; 63 \%)$. The CPOT and FLACC were specifically mentioned as the tools in use at the time of the survey. Echegaray-Benites et al. (2014) reported on the validation of the CPOT with brain surgery patients in a neurological intensive care unit. The use of vital signs as an assessment tool for pain was another common finding and was reported by three nurses (38\%) although, Arbour et al. (2014) concluded that vital signs are not specific for pain detection. When queried about the barriers that they experienced when assessing pain in the neuro critically ill patient, the participant responses were varied, including: "not enough support from licensed practitioners"; "the quick decline in neurological patients"; "a change in level of consciousness leads to a CT scan" and "blood pressure not an indicator of pain".

This research study had several limitations. First, the sample size was limited and may not be representative of the population of registered nurses caring for acutely brain injured adult patients. Another limitation was the limited collection of demographic data. Examining the participant's gender and ethnicity may have allowed the investigator to make correlations between culture and the perception of pain management. The study was also limited by being conducted at one site. The average nurses' experience was under 10 years and may not account for a broader knowledge base of more experienced nurses. An extended timeframe for the collection of data may have led to a higher participation rate. Additionally the survey was conducted during a period when the study site was transitioning to a new electronic charting system. This conversion included 
many changes such as a new behavioral pain scale, which may have lead to confusion between the previous pain scale and the new pain scale and influenced participant responses on the survey.

In summary, research reviewed revealed that the ideal pain indicator is self-report and that in the absence of self-report, behavioral pain scales show reliability and validity in the noncommunicative patient. The results of this study have illustrated nurses' perceptions of the barriers to proper assessment and management of pain with the acutely brain injured adult patient. The study participants reported use of two behavioral pain scales, the CPOT and FLACC as well as several other factors that impact the ability to effectively assess and manage pain. The opportunity for nursing education and collaboration with other healthcare disciplines exists to improve pain management with this vulnerable population of patients.

Next, recommendations and implications for advanced practice nursing will be discussed. 


\section{Recommendations and Implications for Advanced Practice Nursing}

The Advanced Practice Registered Nurse (APRN) is in a unique position to advocate for patients and nurses and to identify areas of practice that require improvement to optimize patient outcomes. The APRN has the ability to effect change and is perfectly positioned to provide nurse education and policy enhancement where indicated. The survey revealed several opportunities for practice improvement and those are highlighted next.

Nurses identified the patients' neurological status as the barrier most often seen when assessing and treating pain and also labeled the subjective assessment tools as a barrier. The literature review revealed that the perfect tool to assess pain in the braininjured acutely ill adult patient has yet to be identified. The need for nurse-driven research to explore alternate measures to identify pain in the neurological patient is indicated. Further research is also indicated to better identify the behavioral responses seen with this patient population when they are experiencing pain. In the absence of typical behaviors like body movements, muscle rigidity, and asynchrony with mechanical ventilation, alternative physiological measures may be of potential interest as an option to the behavioral scales used today. The treatment selections available to manage pain once it has been identified were not explored with this study. Nurse's knowledge of the pharmacologic agents and alternatives to medication to treat patient's pain in critical care is another topic to investigate and further study is indicated. The accurate detection and treatment options for pain with this vulnerable group of critically ill patients will improve outcomes. APRNs possess the skills and training to lead this initiative. 
The survey also revealed that several participants labeled patient vital signs as an indicator that the patient is experiencing pain. Given that the research disputes this fact, an opportunity for nursing education exists. To address this knowledge deficit, the APRN should provide clinical updates on pain management and assessment tools. The APRN is poised to lead nursing education on this topic using evidence-based practice. The APRN is skilled at identifying existing research and disseminating the findings to improve bedside practice. The nurses' perceptions about vital signs as an indication of pain may also provide a clue on the pain behaviors of the neurocritically ill patient and given the limited research on this topic this is another area that may indicate a need for further study. The role of the APRN is to lead and empower nurses with the evidence and act as a role model to elevate practice and improve outcomes. The APRN also has the ability to impact other members of the interdisciplinary team.

Additionally, the survey also exposed a potential barrier with a health care system related issue. Nurses identified that delays with pharmacy verification time frame for new medication orders occurs often (mean score 2.91) and is a perceived barrier. This issue is an opportunity for the APRN to become involved on the systems level and drive policy improvement by identifying the stakeholders and collaborating with the multidisciplinary team to address the issue. As a leader with strong interpersonal skills the APRN can advocate for nurses and patients to facilitate change that improves outcomes on a system wide basis. Furthermore, the APRN can advocate for policy change at the state and national levels through involvement in professional organizations and initiatives. 
The opportunities for the APRN as change agent, role model, clinical expert and team leader are numerous. This research study highlights several areas where the Advanced Practice of Nursing can act as each of these and make a difference. 


\section{References}

Arbour, C., Choiniere, M., Topolovec-Vranic, J., Loiselle, C. G., \& Gelinas, C. (2014). Can fluctuations in vital signs be used for pain assessment in critically ill patients with a traumatic brain injury. Pain Research and Treatment, 1-11. http://dx.doi.org/10.1155/2014/175794

Assessing pain in the critically ill. (2014). Critical Care Nurse, 34(1), 81-83. Retrieved from http://ccn.aacnjournals.org/

Bonnel, W., \& Smith, K. V. (2014). Proposal writing for nursing capstones and clinical projects. New York, NY: Springer Publishing Company, LLC.

Curley, M. A. (1998, January). Patient-nurse synergy: optimizing patients' outcomes. American Journal of Critical Care, 7(1), 64-72.

Echegaray-Benites, C., Kapoustina, O., \& Gelinas, C. (2014). Validation of the use of the Critical-Care Pain Observation Tool (CPOT) with brain surgery patients in the neurosurgical intensive care unit. Intensive and Critical Care Nursing, 1-9. http://dx.doi.org/10.1016/j.iccn.2014.04.002

Gelinas, C., Fillion, L., Puntillo, K. A., Viens, C., \& Fortier, M. (2006). Validation of the critical-care observation tool in adult patients. American Journal of Critical Care, 15(4), 420-427. Retrieved from http://ajcc.aacnjournals.org/

Gelinas, C., Klein, K., Naidech, A. M., \& Skrobik, Y. (2013). Pain, sedation, and delirium management in the neurocritically ill: Lessons learned from recent research. Seminars in Respiratory and Critical Care Medicine, 34(2), 236-243. http://dx.doi.org/10.1055/s-0033-1342986 
Gottschalk, A., \& Yaster, M. (2009). The perioperative management of pain from intracranial surgery. Neurocritical Care, 10(3), 387-402. http://dx.doi.org/10.1007/s12028-008-9150-3

Helms, J. E., \& Barone, C. P. (2008). Physiology and treatment of pain. Critical Care Nurse, 28(6), 38-49. Retrieved from http://ccn.aacnjournals.org

Herr, K., Coyne, P. J., McCaffrey, M., Manworren, R., \& Merkel, S. (2011). Pain assessment in the patient unable to self-report: position statement with clinical practice guidelines. Pain Management Nursing, 12(4), 230-250. http://dx.doi.org/10.1016/j.pmm.2011.10.002

Jho, H. J., Kim, Y., Kong, K. A., Kim, D. H., Choi, J. Y., Nam, E. J., ... Koh, S. (2014). Knowledge, practices, and perceived barriers regarding cancer pain management among physicians and nurses in Korea: A nationwide multicenter survey. Plos One, 9, 1-7. http://dx.doi.org/10.1371/journal.pone.0105900

Lee, K., Oh, H., Suh, Y., \& Seo, W. (2013, December). Patterns and clinical correlates of pain among brain injury patients in critical care assessed with the critical care pain observation tool. Pain Management Nursing, 14(4), 259-267. http://dx.doi.org/10.1016/j.pmn.2011.05.005

McCance, K. L., Huether, S. E., Brashers, V. L., \& Rote, N. S. (2010). Pathophysiology: The biologic basis for disease in adults and children (6th ed.). Maryland Heights, MO: Mosby Elsevier.

McEwen, M., \& Wills, E. M. (2011). Theoretical basis for nursing (3rd ed.). Philadelphia, PA: Lippincott Williams \& Wilkins. 
Pain: Current understanding of assessment, management, and treatments. (n.d.). Retrieved from http://www.americanpainsociety.org/uploads/pdfs/npc/section_1.pdf

Puntillo, K. A., Smith, D., Arai, S., \& Stotts, N. (2008). Critical care nurses provide their perspectives of patients' symptoms in intensive care units. Heart \& Lung: The Journal of Acute and Critical Care, 37(6), 466-475. http://dx.doi.org/10.1016/j.hrtlng.2008.02.002

Puntillo, K., Pasero, C., Li, D., Mularski, R. A., Grap, M., Erstad, B. L., ... Gilbert, H. C. (2009). Evaluation of pain in ICU patients. CHEST, 135(4), 1069-1074. http://dx.doi.org/10.1378/chest.08-2369

Rejeh, N., Ahmadi, F., Mohammadi, E., Anoosheh, M., \& Kazemnejad, A. (2008). Barriers to, and facilitators of post-operative pain management in Iranian nursing: A qualitative research study. International Nursing Review, 468-475. http://dx.doi.org/10.4037/ajcc2012611

Riker, R. R., \& Fraser, G. L. (2013, March). The new practice guidelines for pain, agitation, and delirium. American Journal of Critical Care, 22(2), 153-157. http://dx.doi.org/doi.org/10.4037/ajcc2013480

Rose, L., Smith, O., Gelinas, C., Haslam, L., Dale, C., Luk, E., ... McGillion, M. (2012). Critical care nurses' pain assessment practices: a survey in Canada. American Journal of Critical Care, 21(4), 251-259. http://dx.doi.org/Retrieved from

Roulin, M., \& Ramelet, A. (2012). Pain indicators in brain-injured critical care adults: An integrative review. Australian College of Critical Care Nurses, 110-118. http://dx.doi.org/10.1016/j..aucc.2011.10.002 
Stites, M. (2013). Observational pain scales in critically ill adults. Critical Care Nurse, 33(3), 68-78. http://dx.doi.org/dx.doi.org/10.4037/ccn2013804

Subramanian, P., Allock, N., James, V., \& Lathlean, J. (2011). Challenges faced by nurses in managing pain in a critical care setting. Journal of Clinical Nursing, 1-9. http://dx.doi.org/10.1111/j.1365-2702.2011.03789.x

Swieboda, P., Filip, R., Prystupa, A., \& Drozd, M. (2013). Assessment of pain: types, mechanism and treatment. Retrieved from http://aaem.pl/abstracted.php?level=4\&id_issue $=873482$

Voepel-Lewis, T., Zanotti, J., Dammeyer, J., \& Merkel, S. (2010). Reliability and validity of the face, legs, activity, cry, consolability behavioral tool in assessing acute pain in critically ill patients. American Journal of Critical Care, 19(1), 55-61. http://dx.doi.org/10.4037/ajcc2010624 


\section{Appendix A \\ Informational Letter}

Neuroscience Nurse's Perceptions of the Barriers to Identifying and Treating Pain in the Acutely BrainInjured Adult Patient

April 2015

Dear Colleague,

You are being asked to participate in a research study about nurses' perceptions of the barriers to assessing and managing pain in the Neurocritical Intensive Care Unit. This study is in partial fulfillment of a Masters of Science in Nursing at Rhode Island College. You are identified as a possible participant if you are employed by RIH in the Neurocritical ICU as a staff nurse at the patient bedside. The purpose of the research is to explore nurse's perceptions about pain management with the neurocritically ill adult patient who is unable to communicate and identify barriers to providing adequate pain assessment and pain treatment. If you choose to participate, you will be asked to complete a short survey consisting of 2 openended questions and 15 items to rank on a 4-point scale. The survey should take $5-10$ minutes. Surveys will be located in a marked manila envelope located in this break room. Participation is optional and if you choose to complete the survey you may opt out at any time or choose to only complete the questions you are comfortable with. There are no identified risks associated with participating in this survey. Your responses are anonymous and will remain confidential and only the faculty advisor and I will review them. There are no direct benefits to you for participating in this study. If you have any questions about your rights as a research subject please feel free to call our Research Protections Office Director, Janice Muratori, at 401-444-6897. Once the survey is completed, please place it in the sealed box located on the bookcase in the break room. If you have any questions, please let me know or email me at kiannotti_8976@email.ric.edu or contact Joan Walsh at jwalsh1@lifespan.org. By completing this survey you have agreed to participate in this research project.

Regards,

Kim Iannotti, BSN, RN, MSN Student

Joan Walsh, MSN, APRN, CCNS-BC 
Appendix B

\section{Nurse Survey}

Please complete the following questions related to barriers that nurse's face with the assessment of pain in the neurologically critically injured adult patient.

Your answers will be confidential.

Please circle:

\begin{tabular}{|c|c|c|c|c|}
\hline Age & $22-33$ & $34-44$ & $45-55$ & 56 or older \\
\hline $\begin{array}{l}\text { Years of nursing } \\
\text { experience }\end{array}$ & $0-10$ & & $11-20$ & 21 or more \\
\hline $\begin{array}{l}\text { Education } \\
\text { Level }\end{array}$ & Diploma & Associates & Bachelors & Masters \\
\hline
\end{tabular}

Briefly describe your practice of pain assessment with the neurologically injured adult patient who is unable to communicate.

What are some of the barriers you feel as a nurse when assessing and managing pain in this patient population? 
The following are a series of questions related to how frequently you have encountered specific barriers to pain assessment. They are categorized by patient, medical staff and health care system barriers. Please circle the number that best describes your experience according to the scale $1-4$.

\section{Never}

\section{Patient Related Barriers}

1. Declining neurological status of patient

2. Family members at the bedside

3. Effect of patient sedation level

4. Patient has medication tolerance

\section{Medical Staff Related}

Barriers

5. Subjective assessment tools

6. Insufficient RN knowledge

7. Inadequate $\mathrm{RN}$ experience

8. RN time constraints

9. $\mathrm{RN}$ reluctance to use opioids

10. MD reluctance to prescribe opioids

\section{Health Care System Related Barriers}

11. Stock issues with medication in Omnicell

12. Inadequate staffing

13. Inadequate pain assessment tools

14. Incorrect medication indication listed on order

15. Pharmacy verification time frame for new med order

\section{Some \\ Times}

Often 